\title{
Knowledge Towards Energy Drinks Consumption and Related Factors Among Young Male Athletes in the United Arab Emirates
}

\author{
Aisha A. Almulla ${ }^{1}$, Hadia Radwan ${ }^{2} \&$ Nada Al Adeeb ${ }^{1}$ \\ ${ }^{1}$ Community Nutrition Department, Tawam Hospital- in affiliation with Johns Hopkins Medicine, Abu Dhabi \\ Health Services Company (SEHA), Abu Dhabi, United Arab Emirates \\ ${ }^{2}$ Department of Clinical Nutrition and Dietetics, College of Health Sciences, Research Institute of Medical and \\ Health Sciences (RIMHS), University of Sharjah, Sharjah, United Arab Emirates \\ Correspondence: Aisha Abdalla Almulla, Community Nutrition Department- Tawam Hospital- in affiliation with \\ Johns Hopkins Medicine, Abu Dhabi Health Services Company (SEHA), Abu Dhabi, United Arab Emirates. Tel: \\ 97-137-074-603. E-mail: aialmulla@seha.ae
}

Received: February 18, 2019 Accepted: March 18, 2019 Online Published: March 20, 2019

doi:10.5539/gjhs.v11n5p1 URL: https://doi.org/10.5539/gjhs.v11n5p1

\begin{abstract}
Objectives: We aim to investigate the knowledge towards Energy Drinks (EDs) consumption and related factors among young male athletes in the United Arab Emirates (UAE).

Subjects and Methods: A cross-sectional study included 688 young male athletes from Al Ain sports club aged between 7 to 18 years. Data were collected using a modified version of a validated questionnaire from the European Food Safety Authority.

Results: Overall EDs consumption was $24 \%$. About $44 \%$ of the athletes consumed EDs one to two times per month. Athletes who were training between 5-7 days per week consumed significantly more EDs compared to those who were training 3-4 days per week ( $81 \%$ vs. $15 \%, P<0.001)$. Athletes aged $7-12$ years were 2.4 times more likely to consume EDs than athletes aged 13-18 years $(P<0.001)$. Moreover, athletes living with both parents were significantly less likely to consume EDs compared to those living with a single parent $(P=0.01)$. Knowledge score about EDs consumption was significantly higher for non EDs consumers compared to EDs consumers $(P<0.001)$.

Conclusions: EDs consumption among young male athletes was moderate. Educational programs are needed to increase the awareness regarding EDs consumption and its potential adverse effects among the young athletes. A regulation policy for EDs consumption should be addressed and consideration of labels with EDs contents and age identification is highly recommended.
\end{abstract}

Keywords: adolescent, athletes, consumption, energy drinks, knowledge

\section{Introduction}

Energy Drinks (EDs) has become one of the most popular beverages worldwide. They are defined as any type of non-alcoholic beverages that contains caffeine as a main ingredient, taurine, vitamins, and other ingredients combination (such as guarana and ginseng, etc.) (Metrology, 2015; Zucconi, 2013). They are marketed as to relieve fatigue and improve mental alertness, in contrast with sports or isotonic drinks which are intended to help athletes rehydrate after exercise (Campbell et al., 2013; Schneider \& Benjamin, 2011). EDs marketing targets athletics as the primary target population, but as the expanding of EDs marketing into a different niche, teenagers and young adults are today the target population for EDs consumption as this group is more attracted to advertisements of these type of products (Heckman, 2010; Lal, 2007).

Many reports on the adverse effects of EDs consumption have been received by poison control centers and regulatory authorities (Ali, Rehman, Babayan, Stapleton, \& Joshi, 2015; FDA, 2012; Gunja, 2012; Seifert, Schaechter, Hershorin, \& Lipshultz, 2011). These reports included cardiac, neurological and gastrointestinal adverse effects. An excess amount of caffeine can lead to many negative health effects such as sleep disturbance, anxiety, jitteriness, gastrointestinal effects, tachycardia, and other cardiac symptoms and in some rare cases seizures and death (Harris \& Munsell, 2015; Reissig, Strain, \& Griffiths, 2009; Seifert et al., 2011). According to the U.S. Food and Drug Administration (FDA), the higher limit of moderate caffeine consumption among healthy 
adult people is $400 \mathrm{mg} /$ day (FDA, 2018). Health Canada issued recommendations for maximum caffeine intake levels for children aged 4 to 12 years to be between $45-85 \mathrm{mg}$ caffeine per day and for children aged 13 years and above caffeine consumption should not exceed $2.5 \mathrm{mg} / \mathrm{kg} /$ day (Canada, 2012).

Data from the European Food Safety Authority (EFSA) showed that the consumption of EDs was $68 \%$ among adolescents, $30 \%$ among adults and $18 \%$ among children ( $<10$ years old) (Zucconi, 2013). O'Brien et al. found that $34 \%$ of EDs consumers were aged between 18 to 24 years in the USA (O'Brien, McCoy, Rhodes, Wagoner, \& Wolfson, 2008). Moreover, Gallimberti et al. reported a significant increase in EDs consumption from $18 \%$ among sixth grade to $56 \%$ among eight-grade adolescent students (Gallimberti et al., 2013). EDs consumption among college students in the United Arab Emirates (UAE) was reported to be 92\% (Shery Jacob, 2013). There is a scarcity of studies on EDs consumption among young athletes. We aimed to investigate the knowledge towards EDs consumption and related factors among young male athletes in the UAE.

\section{Materials and Methods}

\subsection{Study Protocol}

This cross-sectional study was carried out during the period from May to October 2017 among young male athletes in Al Ain Sports Club, Al Ain city, Abu Dhabi, UAE. A convenient sample of total of 688 male athletes aged between 7 to 18 years from different sports disciplines were selected.

A structured and validated questionnaire of 37 questions was created based on a previously validated questionnaire used for gathering consumption data on specific consumer groups of EDs by the European Food Safety Authority (EFSA) (Zucconi, 2013). The questionnaire was modified and adapted to our culture and objectives and was administered in both English and Arabic. It was translated from English to Arabic and back-translated. The questionnaire was reviewed by three other nutritionists and pilot tested on 27 young athletes to ensure the validity and clarity of the questions.

This study is approved by Al Ain Medical District Human Research Ethics Committee (CRD504/17, Protocol No.17-27). The consent was obtained from the participant's parent. All study data and participant's information were handled confidentially and coded, and no one but the research team from the Community Nutrition Department had access to it.

\subsection{Data Collection Tools}

The questionnaire consisted of 6 sections: section (1) demographic data (gender, age groups (7-12 years and 1318 years), weight, height, general health status and family type (living with both parents, single parent, other), average sleeping duration during weekdays ( $<7$ hours, 7-9 hours, $<9$ hours), Type of sports: team sports (football, basketball, handball, vollyball) or individual sports (swimming, JiuJitsu); (2) overall beverages consumption; (3) EDs consumption frequency (during the past 3 days and the past year), can size, location, reasons for consumption, preferred brand, choice of sugar or sugar free, parental EDs consumption; (4) Physical Activities (PA) [exercise frequency (5-7 days per week, 3-4 days per week, 1-2 days per week), EDs consumption before/during/after exercise and number of cans per session]; (5) Other caffeinated beverages (coffee, tea, hot chocolates, and cola) consumption frequency, cup or can size and caffeine and sugar choice); (6) knowledge about EDs price, caffeine and vitamins contents.

Each athlete was interviewed face-to-face by a nutritionist. Pictures and samples of EDs products with all available sizes were used during the interview. Body Mass Index (BMI) of the athletes were measured and calculated as weight in kilograms $(\mathrm{kg}) /(\text { height in meter) })^{2}$. BMI was classified according to the Centers for Disease Control and Prevention (CDC) Growth Charts into underweight (less than $5^{\text {th }}$ percentile); healthy weight ( $5^{\text {th }}$ percentile to the $85^{\text {th }}$ percentile); overweight $\left(85^{\text {th }}\right.$ percentile to less than the $95^{\text {th }}$ percentile) and obese (equal to or greater than the $95^{\text {th }}$ percentile). (CDC, 2015)

\subsection{Statistical Analysis}

Data from all the questionnaires were coded and entered using SPSS (Statistical Package for the Social Sciences, version 23). Descriptive and frequency analysis was used to analyze the baseline athletes characteristics. Pearson $\mathrm{x}^{2}$ test was used to assess differences in the distribution of frequency of replies and to analyze the influence of selected related factors (BMI categories, family type and frequency of PA) on overall EDs consumption). Logistic regression was performed to test the effects of various factors (age group, family type, average sleeping hours per weekdays and frequency of PA) on overall EDs consumption.

For each athlete, a knowledge score (K score) ranging from 4 to 8 was calculated based on the number of the correct answers to four questions. The higher the score, the lower the knowledge towards EDs. Independent t-test 
was used to test if the K score means differs based on overall EDs consumption. Simple linear regression was used to study if a $\mathrm{K}$ score can predict overall EDs consumption, age groups, and family type. In our study, the significant criteria were set at $P<0.05$ and were used for all the statistical analysis.

\section{Results}

\subsection{Athletes Characteristics}

Table 1 describes athletes sociodemographic characteristics according to EDs consumption. The study included 688 male athletes (mean age $11.5 \pm 2.5$ years, mean BMI $=19 \pm 4.1 \mathrm{~kg} / \mathrm{m}^{2}$ ). Among all athletes, $21 \%$ were either overweight or obese. Around $87 \%$ of all the athletes lived with both parents and $12 \%$ lived with a single parent. The majority of the Athletes reported no health problems (92\%).

Table 1. Athletes characteristics as related to EDs consumption $(\mathrm{n}=688) * *$

\begin{tabular}{|c|c|c|c|}
\hline \multirow{3}{*}{ Socio-Demographic data } & \multicolumn{3}{|c|}{ Overall EDs consumption } \\
\hline & Yes & No & Total \\
\hline & $\mathrm{n}(\%)$ & $\mathrm{n}(\%)$ & n (\%) \\
\hline \multicolumn{4}{|l|}{ Age groups (Years) } \\
\hline $7-12$ & $69(42)$ & $371(58)$ & $440(64)$ \\
\hline $13-18$ & $94(71)$ & $150(29)$ & $244(36)$ \\
\hline \multicolumn{4}{|l|}{ BMI $\left(\mathrm{kg} / \mathrm{m}^{2}\right)$} \\
\hline Underweight & $12(9)$ & $29(6)$ & $41(6)$ \\
\hline Normal & $95(69)$ & $309(68)$ & $404(59)$ \\
\hline Overweight & $17(12)$ & $70(15)$ & $87(13)$ \\
\hline Obese & $13(10)$ & $49(11)$ & $62(9)$ \\
\hline \multicolumn{4}{|l|}{ Family type* } \\
\hline Both parents & $133(82)$ & $468(89)$ & $601(87)$ \\
\hline Single parent & $28(17)$ & $56(11)$ & $84(12)$ \\
\hline Other & $2(1)$ & $1(0.2)$ & $3(0.4)$ \\
\hline \multicolumn{4}{|c|}{ Average sleeping weekdays (hours) } \\
\hline$<7$ & $38(23)$ & $50(10)$ & $88(13)$ \\
\hline 7-9 & $101(62)$ & $332(63)$ & $433(63)$ \\
\hline$>9$ & $24(15)$ & $142(27)$ & $166(24)$ \\
\hline \multicolumn{4}{|l|}{ Type of sports } \\
\hline Team sports & $139(85)$ & $462(88)$ & $601(87)$ \\
\hline Individual sports & $24(15)$ & $63(12)$ & $87(13)$ \\
\hline \multicolumn{4}{|l|}{ PA frequency" } \\
\hline 1-2 days/week & $7(4)$ & $50(11)$ & $57(8)$ \\
\hline 3-4 days/week & $24(15)$ & $120(26)$ & $144(21)$ \\
\hline 5-7 days/week & $132(81)$ & $295(63)$ & $427(62)$ \\
\hline
\end{tabular}

Note. $\mathrm{BMI}=$ body mass index, $\mathrm{PA}=$ physical activities.

**Some values were missing for some variables.

*Significant $P<0.05$.

Interestingly, athletes living with both parents consumed significantly fewer EDs (89\%) as compared to athletes living with a single parent $(11 \%, P=0.01)$. Moreover, athletes who trained between 5-7 days per week consumed significantly more EDs compared to those who trained between $3-4$ days per week ( $81 \%$ vs. $15 \%, P<0.001)$, Table 
1.

\subsection{Energy Drinks Consumption}

In our study, the overall EDs consumption among young male athletes was $24 \%(n=163)$. The majority consumed at least one can once or twice per month $(44 \%) .22 \%$ of athletes parents consumed EDs sometimes, the majority $(16 \%)$ were athletes fathers. In terms of the preferred brands, two brands of the tested emerged to capture market share of over $80 \%$. The most popular brands of EDs were Redbull (54\%) and PowerGold (29\%). The majority of athletes consumed $250 \mathrm{ml}$ EDs can size $(87 \%)$. The main reasons for EDs consumption by the athletes were its good taste (54\%), energy/performance enhancement (19\%), and friends influence (20\%), Figure 1. Regarding EDs consumption as related to PA, 17\% of athletes reported never consumed EDs during PA, 5\% reported sometimes consumed before and/or after or during PA, 2\% reported EDs consumption always before or after PA.

\section{Reasons for EDs consumption}

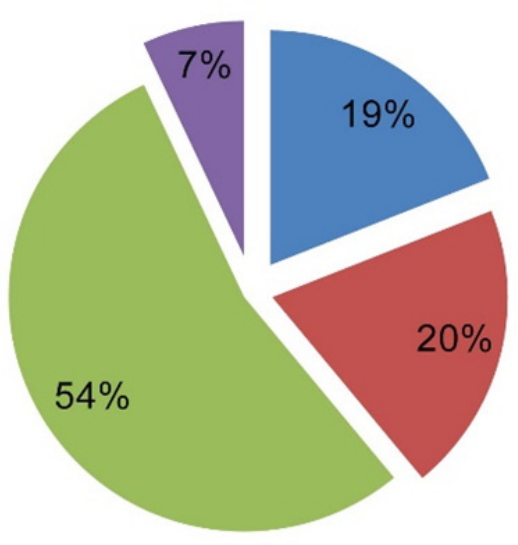

- Energy/performance enhancment

- Friends influence

= Good taste

Attention and focus improvement

Figure 1. Reasons for Energy Drinks consumption among young male athletes

\subsection{Overall EDs Consumption and Related Factors}

Age and sleeping hours were significant predictors to EDs consumption, Table 2. Athletes aged 7-12 years were 2.4 times more likely to consume EDs than athletes aged 13-18 years after controlling for all other factors in the model. Additionally, athletes sleeping between 7-9 hours and those more than 9 hours were more likely to consume EDs compared to athletes sleeping less than 7 hours (Table 2). A Pearson correlation analysis showed a positive correlation between EDs consumption and average weekdays sleeping hours $(\mathrm{r}=0.186, \mathrm{n}=687, P<$ $0.001)$. On the other hand, a negative correlation was shown between age groups and EDs consumption $(\mathrm{r}=-0.257$, $\mathrm{n}=684, P<0.001)$. 
Table 2. Logistic regression of overall EDs consumption with selected variables $(n=624)$

\begin{tabular}{lll}
\hline Variables & OR & $\mathbf{9 5 \%}$ CI \\
\hline Age groups (years) & & \\
$13-18$ (ref) & 2.38 & $1.56,3.63^{*}$ \\
$7-12$ & & \\
\hline Family type & 0.6 & $0.35,1.02$ \\
Both parents (ref) & 0.25 & $0.02,3.6$ \\
Single parent & & \\
Others & & \\
\hline Average sleeping weekdays (hours) & 1.73 & $1.04,2.89^{*}$ \\
$<7$ (ref) & 2.31 & $1.19,4.52^{*}$ \\
$7-9$ & & \\
$>9$ & & \\
\hline PA frequency & & \\
$5-7 \mathrm{~d} /$ week (ref) & 1.55 & $0.92,2.62$ \\
3-4d/week & 2.02 & $0.86,4.74$ \\
1-2d/week & & \\
\hline
\end{tabular}

Note. $\mathrm{OR}=$ Odds Ratio; $\mathrm{CI}=$ Confidence Interval; $\mathrm{PA}=$ physical activities.

*Significant $P<0.05$.

\subsection{Knowledge Towards Overall EDs Consumption}

Around $82 \%$ of the athletes didn't know that EDs contained caffeine and only $20 \%$ believed that EDs contained vitamins. The majority of athletes (76\%) assumed that EDs and soft drinks are different.

The average knowledge score $(\mathrm{K})$ of EDs consumption among all the athletes was $6.5 \pm 0.96(n=687)$. We found that $\mathrm{K}$ score was significantly higher for non EDs consumers $6.6 \pm 0.96(\mathrm{n}=524)$ compared to $\mathrm{K}$ score for EDs consumers $6.05 \pm 0.88(\mathrm{n}=163)(P<0.001)$. These results suggest that athletes who were not consuming EDs had lower knowledge towards EDs consumption.

EDs consumption and age groups were significant predictors of $\mathrm{K}$ score as described in Table 3. These results suggest that as the age increases, knowledge towards EDs increases and as the overall EDs consumption increases, knowledge towards EDs decreases.

Table 3. Multiple linear regression of K score with related factors

\begin{tabular}{lllll}
\hline Variables in the model & b & SE b & $\boldsymbol{\beta}$ & $\mathbf{9 5 \%}$ CI \\
\hline Overall EDs consumption & 0.24 & 0.044 & 0.213 & $0.16,0.33^{*}$ \\
Age groups & -0.21 & 0.078 & -0.102 & $-0.36,-0.054^{*}$ \\
Family type & -0.038 & 0.103 & -0.014 & $-0.24,0.17$ \\
\hline
\end{tabular}

Note. $\mathrm{b}$ and $\mathrm{SE} \mathrm{b}=$ unstandardized coefficient and its standardized error; $\beta=$ the standardized coefficient; $\mathrm{CI}=\mathrm{Confidence}$ Interval

*Significant $P<0.05$.

\section{Discussion}

This study reported that overall EDs consumption among male athletes aged 7 to 18 years was $24 \%$. Forty-four percent of athletes in this study reported EDs consumption 1-2 times per month. Similarly, The EDs consumption among adolescents in Bahrain was 2 to 3 times per week (28.8\%) and 1-2 times per month (15\%) (Maryam, 2015). 
While lower EDs consumption rate was reported among adolescents aged 11-13 years old in Italy (20\%) (Gallimberti et al., 2013). Musaiger et al. (Musaiger \& Zagzoog, 2013) reported that about 55\% of adolescents consumed EDs once or more each week. In our study, it has been found that athletes aged 7-12 years were more likely to consume EDs than athletes aged 13-18 years. Similar to other, our study showed that the consumption rate decline with increased age (Simon, 2007). In contrast, Gallimberti L. et al. (Gallimberti et al., 2013) demonstrated that EDs consumption increased steadily with age where eight graders $(50 \%)$ consumed more EDs as compared to sixth grader (18.6\%).

Our study showed that athletes living with both parents were less likely to consume EDs (89\%). However, some athletes reported that $22 \%$ of their parents consumed EDs sometimes. This indicates the influence of parents on their children's attitudes towards EDs consumption. It was shown that parental lack of awareness about caffeine-related health risks on young children and the differences between EDs and other soft drinks was the reason for allowing their children to consume EDs (Oddy \& O'Sullivan, 2009).

In contrast to Koivusilta L. et al. (Koivusilta, Kuoppamaki, \& Rimpela, 2016), Our study showed that athletes who slept 7 hours and more were more likely to consume EDs than athletes sleeping less than 7 hours. This could be explained that athletes who sleep longer hours felt that they needed to drink EDs in order to feel energized for their sports activity. Nowak D. et al (Nowak \& Jasionowski, 2016) showed that $28 \%$ of respondents claimed that EDs gave them a boost of energy. Similarly, our study showed that $19 \%$ of the athletes consumed the EDs to increase their energy and enhance their performance. Caffeine is the primary source of energy in EDs. It has been shown that caffeine enhances physical performance in adults by improving concentration, reduces fatigue, enhance alertness and power (Paluska, 2003). However, these effects vary according to the consumer age, sex and caffeine dependency (Schneider \& Benjamin, 2011). Two randomized studies among elite junior athletes showed that pre-exercise ingestion of EDs had a positive effect on participants sports performance (Abian-Vicen et al., 2014; Gallo-Salazar et al., 2015), however both studies involved small numbers of participants thus this should further be investigated in a bigger sample with concerns to the long-term effects of EDs on physical performance and overall health issues.

It has been showed that some adolescents consume EDs for their perceived physiological benefits without being aware of the potential health risks of these drinks (O'Dea, 2003). Similar to others (Maryam M. Nassaif, 2015; Musaiger \& Zagzoog, 2013; Nowak \& Jasionowski, 2016; Zucconi, 2013), 54\% of EDs consumers in our study reported that the main reason for consuming EDs was its good taste. In contrast with another study, we found that $82 \%$ of the athletes didn't know that EDs contained caffeine and $20 \%$ believed that EDs contained vitamins (Musaiger \& Zagzoog, 2013). The majority of athletes in our study believed that EDs and soft drinks are different (76\%), which was in contrast to Musaiger et al. (Musaiger \& Zagzoog, 2013) who found that $67 \%$ of adolescents considered EDs similar to soft drinks. Hardy. et al (Hardy, Kliemann, Evansen, \& Brand, 2017) investigated the association between EDs consumption and overall knowledge score and found that users of EDs scored significantly lower on the section of food/nutrients sources and disease knowledge than did non EDs users. Caffeine content in EDs ranges from 50-505 $\mathrm{mg}$ in a can or bottle depending on the capacity. This amount is equal to or even exceeds the amount of caffeine in a cup of coffee (Clauson, Shields, McQueen, \& Persad, 2008; Reissig et al., 2009). In addition to EDs consumption, athletes in our study also consumed other caffeinated beverages such as soft drinks (23\%), and tea (39\%) which can further increase their daily caffeine intake. An excess amount of caffeine can lead to many negative health effects such as sleep disturbance, anxiety, jitteriness, gastrointestinal effects, tachycardia, and other cardiac symptoms and in some rare cases seizures and death (Harris \& Munsell, 2015; Reissig et al., 2009; Seifert et al., 2011).

Different countries have set their own regulatory policies regarding labeling, distribution, and sale of EDs with a high content of caffeine. Regulations of the European enforced additional caffeine labeling for EDs with $150 \mathrm{mg} / \mathrm{l}$ caffeine (Thomson, 2010). In all EU Member States, EDs can be sold but with specific regulations including setting rules for sales to youths. For example, in Sweden, some products sales are regulated by pharmacies and sales to children under the age of 15 years are illegal (Oddy \& O'Sullivan, 2009). In Canada, EDs require warning labels, the maximum daily consumption amount and advise against mixing EDs with alcohol (Temple, 2009). In the UAE, the Emirates Authority for standards and Metrology (ESMA) have set regulation policies for EDs labelling such as not allowing pregnant and lactating women, persons under the age of 16 years, persons with sensitivity to caffeine, and those with heart and arterial problems, as well as athletics during exercises to drink EDs (Metrology, 2015). It is necessary to amend the UAE standards for EDs for those under the age of 18 years by placing restrictions on EDs marketing, limiting EDs sales places, active enforcement of a minimum purchase age with age verification card. Moreover, relevant authorities should be instructed to discourage mixing EDs with other beverages. 


\section{Conclusions}

EDs consumption rate was moderate among young male athletes in the UAE. Educational programs are needed to increase awareness regarding EDs consumption and its potential adverse effects. A regulation policy for EDs consumption should be addressed, and consideration of warning labels with EDs contents and age identification is highly recommended.

\subsection{Strength and Limitation}

To our knowledge, this is the first study investigating the EDs consumption prevalence among young athletes. The face-to-face questionnaire interview gave more accurate responses compared to self-reporting data. We used a modified validated questionnaire from the EFSA study to examine practices of EDs with reliable measurements.

We have to acknowledge that this study has certain limitations. Our study is a cross-sectional study, so implications of casual association cannot be accurately made. Additionally, athletes included in this study may not be representative of all sports athletes in the UAE.

\subsection{Implications}

The present study gave unique information regarding the prevalence of EDs consumption among children and adolescents in Al Ain city. The study also investigated the related influence factors of EDs consumption and knowledge towards EDs consumption among athletes.

On October 1, 2017, the UAE Federal Tax Authority has implemented excise tax at a rate of $100 \%$ on EDs. it would be very interesting to conduct a follow-up study after tax implementation on EDs to compare it with our findings.

\section{Acknowledgments}

The authors are grateful to all athletes who have participated in the study and to Al Ain sports club for their support. A special thanks to Mr. Faisel Aziz for his contribution in double checking our statistical data analysis and Dr. Khaled Dougman for his contribution in reviewing the preliminary results of the study.

\section{Author Contributions}

AAA contributed to conception and design, acquisition of data, data analysis and interpretation. Both AAA and HR drafted the paper and critically reviewed the manuscript; NA contributed to study design, data collection and reviewed the manuscript. All authors gave the final approval of the version to be published.

\section{Competing Interests Statement}

The authors declare that there are no competing or potential conflicts of interest.

\section{References}

Abian-Vicen, J., Puente, C., Salinero, J. J., Gonzalez-Millan, C., Areces, F., Munoz, G., . . Del Coso, J. (2014). A caffeinated energy drink improves jump performance in adolescent basketball players. Amino Acids, 46(5), 1333-1341. https://doi.org/10.1007/s00726-014-1702-6

Ali, F., Rehman, H., Babayan, Z., Stapleton, D., \& Joshi, D. D. (2015). Energy drinks and their adverse health effects: A systematic review of the current evidence. Postgrad Med, 127(3), 308-322. https://doi.org/10.1080/00325481.2015.1001712

Campbell, B., Wilborn, C., La Bounty, P., Taylor, L., Nelson, M. T., Greenwood, M., . . Kreider, R. B. (2013). International Society of Sports Nutrition position stand: energy drinks. J Int Soc Sports Nutr, 10(1), 1. https://doi.org/10.1186/1550-2783-10-1

Centers for Disease Control and prevention. (2018, July 3). About Child \& Teen BMI. Retrieved from https://www.cdc.gov/healthyweight/assessing/bmi/childrens_bmi/about_childrens_bmi.html

Clauson, K. A., Shields, K. M., McQueen, C. E., \& Persad, N. (2008). Safety issues associated with commercially available energy drinks. $J$ Am Pharm Assoc (2003), 48(3), e55-63; quiz e64-57. https://doi.org/10.1331/JAPhA.2008.07055

Emirates Authority for Standardization and Metrology. (2015). Energy Drinks, UNITED ARAB EMIRATES. Retrieved from https://www.esma.gov.ae/en-us/Pages/default.aspx

Galimberti, L., Buja, A., Chindamo, S., Vinelli, A., Lazzarin, G., Terraneo, A., . . Baldo, V. (2013). Energy drink consumption in children and early adolescents. Eur $J$ Pediatr, 172(10), 1335-1340. https://doi.org/10.1007/s00431-013-2036-1 
Gallo-Salazar, C., Areces, F., Abian-Vicen, J., Lara, B., Salinero, J. J., Gonzalez-Millan, C., . . Del Coso, J. (2015). Enhancing physical performance in elite junior tennis players with a caffeinated energy drink. Int J Sports Physiol Perform, 10(3), 305-310. https://doi.org/10.1123/ijspp.2014-0103

Government of Canada. (2012, February 16). Caffeine in Food. Retrieved from http://www.hc-sc.gc.ca/fn-an/securit/addit/caf/food-caf-aliments-eng.php

Gunja N, B. J. A. (2012). Energy drinks: health risks and toxicity. Medical Journal of Australia, 196, 46-49. https://doi.org/10.5694/mja11.10838

Hardy, R., Kliemann, N., Evansen, T., \& Brand, J. (2017). Relationship Between Energy Drink Consumption and Nutrition Knowledge in Student-Athletes. J Nutr Educ Behav, 49(1), 19-26.e11. https://doi.org/10.1016/j.jneb.2016.08.008

Harris, J. L., \& Munsell, C. R. (2015). Energy drinks and adolescents: what's the harm? Nutr Rev, 73(4), $247-257$. https://doi.org/10.1093/nutrit/nuu061

Heckman, M. A., Sherry, K. and De Mejia, E. G. (2010). Energy Drinks: An Assessment of Their Market Size, Consumer Demographics, Ingredient Profile, Functionality, and Regulations in the United States. Comprehensive Reviews in Food Science and Food Safety, 9, 303-317. https://doi.org/10.1111/j.1541-4337.2010.00111.x

Koivusilta, L., Kuoppamaki, H., \& Rimpela, A. (2016). Energy drink consumption, health complaints and late bedtime among young adolescents. Int J Public Health, 61(3), $299-306$. https://doi.org/10.1007/s00038-016-0797-9

Lal, G. G. (2007). Getting specific with functional beverages. Food Technol., 61(12), 25-31.

Maryam M. Nassaif, G. J. J. A., Noor A. A. Alaam, Abdulla N. Alderrazi, Muyssar S. Awdhalla, Asokan G. Vaithinathan. (2015). Energy Drink Consumption Practices of Young People in Bahrain. Central Asian Journal of Global Health, 4. https://doi.org/10.5195/CAJGH.2015.216

Musaiger, A., \& Zagzoog, N. (2013). Knowledge, attitudes and practices toward energy drinks among adolescents in Saudi Arabia. Glob J Health Sci, 6(2), 42-46. https://doi.org/10.5539/gjhs.v6n2p42

Nowak, D., \& Jasionowski, A. (2016). Analysis of Consumption of Energy Drinks by a Group of Adolescent Athletes. Int J Environ Res Public Health, 13(8). https://doi.org/10.3390/ijerph13080768

O'Brien, M. C., McCoy, T. P., Rhodes, S. D., Wagoner, A., \& Wolfson, M. (2008). Caffeinated cocktails: energy drink consumption, high-risk drinking, and alcohol-related consequences among college students. Acad Emerg Med, 15(5), 453-460. https://doi.org/10.1111/j.1553-2712.2008.00085.x

Oddy, W. H., \& O'Sullivan, T. A. (2009). Energy drinks for children and adolescents. BMJ, 339. https://doi.org/10.1136/bmj.b5268

O'Dea, J. A. (2003). Consumption of nutritional supplements among adolescents: usage and perceived benefits. Health Educ Res, 18(1), 98-107. https://doi.org/10.1093/her/18.1.98

Paluska, S. A. (2003). Caffeine and exercise. Curr Sports Med Rep, 2(4), $213-219$. https://doi.org/10.1249/00149619-200308000-00008

Reissig, C. J., Strain, E. C., \& Griffiths, R. R. (2009). Caffeinated Energy Drinks -- A Growing Problem. Drug and alcohol dependence, 99(1-3), 1-10. https://doi.org/10.1016/j.drugalcdep.2008.08.001

Schneider, M. B., \& Benjamin, H. J. (2011). Sports drinks and energy drinks for children and adolescents: are they appropriate? Pediatrics, 127(6), 1182-1189. https://doi.org/10.1542/peds.2011-0965

Seifert, S. M., Schaechter, J. L., Hershorin, E. R., \& Lipshultz, S. E. (2011). Health effects of energy drinks on children, adolescents, and young adults. Pediatrics, 127(3), 511-528. https://doi.org/10.1542/peds.2009-3592

Shery Jacob, J. T., Fatima Mohammed, T., \& Yara, A. (2013). Consumption pattern of nutritional health drinks and energy drinks among university students in Ajman, UAE. Gulf Medical Journal, 2(1), 22-26.

Simon, M. J. (2007). Alcohol, energy drinks, and youth: a dangerous mix. Retrieved from San Rafael, CA http://alcoholjustice.org/images/stories/EnergyDrinkReport.pdf

Temple, J. L. (2009). Caffeine Use in Children: What we know, what we have left to learn, and why we should worry. Neuroscience and biobehavioral reviews, $393-806$. https://doi.org/10.1016/j.neubiorev.2009.01.001 
Thomson B., S. S. (2010, April). Risk Profile: Caffeine in Energy Drinks and Energy shots. Retrieved from http://www.foodsafety.govt.nz/elibrary/industry/Risk_Profile_Caffeine-Science_Research.pdf

U.S. Food and Drug Administration. (2012, November 16). Energy "Drinks" and Supplements: Investigations of Adverse Event Reports. Retrieved from https://www.fda.gov/Food/RecallsOutbreaksEmergencies/SafetyAlertsAdvisories/

U.S. Food and Drug Administration. (2018, December 12). Spilling the Beans: How Much Caffeine is Too Much? Retrieved from https://www.fda.gov/ForConsumers/ConsumerUpdates/ucm350570.htm

Zucconi, S. V. C., Adinolfi, F., Gandini, E., Gentile, E., Loi, A., \& Fioriti, L. (2013). Gathering consumption data on specific consumer groups of energy drinks. Parma: Supporting Publications.

\section{Copyrights}

Copyright for this article is retained by the author(s), with first publication rights granted to the journal.

This is an open-access article distributed under the terms and conditions of the Creative Commons Attribution license (http://creativecommons.org/licenses/by/4.0/). 